\title{
O direito à convivência familiar e comunitária de crianças e adolescentes: construção histórica no Brasil
}

\author{
The right to family and community life of children and adolescents: \\ historical building in Brazil
} \begin{abstract}
Klenia Souza Barbosa de Morais ${ }^{2}$
\section{Resumo:}

O trabalho é um estudo teórico sobre a construção legal do direito à convivência familiar e comunitária de crianças e adolescentes. A legislação vigente reconhece que a família é o lugar privilegiado para o desenvolvimento de crianças e adolescentes, sujeitos de direitos, com prioridade absoluta, exigindo um Estado presente, que invista na manutenção dos vínculos familiares. O texto tece considerações conceituais e legais sobre família, convivência familiar e comunitária. Conclui-se que esses dispositivos legais são insuficientes para a efetivação do direito, imprescindível a ação do Estado através de políticas públicas que garantam saúde, educação, trabalho, entre outros, atendendo as reais demandas dos sujeitos envolvidos.
\end{abstract}

Antonia Gomes Furtado

Raffaella Canini ${ }^{3}$

Palavras-chave: Crianças e adolescentes. Acolhimento institucional. Convivência familiar e comunitária. Políticas públicas.

\begin{abstract}
:
The work is a theoretical study on the legal construction of the right to family and community life of children and adolescents. Current law recognizes that the family is the privileged place for the development of children and adolescents, subject to rights, with absolute priority, requiring this State, which invests in maintaining family ties. The text weaves conceptual and legal considerations of family, family and community. Concluded that these legal provisions are insufficient for the realization of the right, essential state action through public policies that ensure health, education, work, among others, meeting the real needs of the individuals involved.
\end{abstract}

Keywords: Children and adolescents. Institutional home. coexistence family and community. Public policy

\section{Introdução}

O processo de institucionalização de crianças e adolescentes, com consequente quebra dos vínculos familiares e comunitários, começa a tomar novos rumos em meados

1 Faculdades Integradas de Patos. Mestre em Serviço Social pela Universidade Federal da Paraíba. E-mail: furtado.antoniag@gmal.com

2 Assistente Social do MDS, Mestre em Serviço Social pela Universidade Federal da Paraíba. E-mail: kleniab@hotmail.com

3 Faculdades Integradas de Patos. Mestre em Serviço Social pela Universidade Federal da Paraíba. E-mail: raffaella.canini@bol.com.br 
da década de 1980 a partir de questionamentos levantados sobre a cultura institucional que marcou historicamente o atendimento à criança e ao adolescente.

No entanto, somente com a promulgação do Estatuto da Criança e do Adolescente (ECA) em 1990 e a afirmação da doutrina de "proteção integral" em detrimento da doutrina da "situação irregular" tem-se a valorização da convivência familiar e comunitária para crianças e adolescentes, partindo do artigo 227 da Constituição de 1988. Deste modo, o Estatuto dita:

Art. 4으 - É dever da família, da comunidade, da sociedade em geral e do poder público assegurar, com absoluta prioridade, a efetivação dos direitos referentes à vida, à saúde, à alimentação, à educação, ao esporte, ao lazer, à profissionalização, à cultura, à dignidade, ao respeito, à liberdade e à convivência familiar e comunitária (BRASIL, 2010, p.13).

Esse direito, agora garantido, ratifica o que já havia sido previsto na Constituição, em seu artigo 224, essas garantias legais são fruto de um processo de efervescência social vivenciada no nosso País na década de 1980, bem como, da pressão de uma série de documentos internacionais que reconheciam direitos atribuídos às crianças e adolescentes. A convivência familiar e comunitária é reforçada em outros artigos do Estatuto, tornando-se um direito com força legal:

Art. 19--Toda criança ou adolescente tem direito a ser criado e educado no seio da sua família e, excepcionalmente, em família substituta, assegurada a convivência familiar e comunitária, em ambiente livre da presença de pessoas dependentes de substâncias entorpecentes (BRASIL, 2010, p.14).

Parece óbvio afirmar que toda criança e adolescente tem direito a viver em família, no entanto, diante do histórico de institucionalização de crianças e adolescentes fez-se necessário à criação de mecanismos legais para sua garantia e que normatizem o período de afastamento do convívio familiar e comunitário como excepcional e transitório.

Fundamentado na legislação brasileira vigente, Simões (2007) coloca que a família constitui instância básica, na qual o sentimento de pertencimento é desenvolvido e mantido, e, também, são transmitidos os valores e condutas pessoais. Desse modo, tratase da mudança do "olhar" e do fazer, não apenas das políticas públicas focalizadas na infância, na adolescência e na juventude, mas extensivos aos demais atores sociais do 
chamado Sistema de Garantia de Direitos ${ }^{4}$, implicando a capacidade de ver essas crianças e adolescentes como sujeitos de direitos e de maneira indissociável do seu contexto social, familiar e comunitário.

Com o intuito de compreender o tema abordado, concorda-se com Rizzini (2006, p 34) no que diz respeito ao entendimento da autora sobre a Convivência Familiar e Comunitária, a saber:

Por convivência familiar e comunitária, entende-se a possibilidade da criança permanecer no meio a que pertence. De preferência junto à sua família, ou seja, seus pais e/ou outros familiares. Ou, caso isso não seja possível, em outra família que a possa acolher. Assim, para os casos em que há necessidade das crianças serem afastadas provisoriamente de seu meio, qualquer que seja a forma de acolhimento possível, deve ser priorizada a reintegração ou reinserção familiar - mesmo que este acolhimento tenha que ser institucional.

Portanto, se realmente há necessidade do afastamento, o acolhimento deve ser provisório, priorizando a reinserção ou reintegração familiar, primeiramente na família de origem e, caso isso não seja possível, em outra família que a possa acolher.

Com certeza, a família tem ganhado centralidade dentro das políticas públicas, sendo ela reconhecida como a responsável pelo cuidado e bem-estar de seus membros. No entanto, é preciso ter clareza sobre os limites e possibilidades dessa centralidade, que não pode representar a responsabilização da família como única fonte de proteção.

Essa relevância da família no tocante às políticas sociais, segundo Mioto (2009), se dá a partir da década de 1970, devido entre outros fatores, ao retrocesso do Welfare State. A diminuição da ação estatal no campo da proteção social coloca o foco na família como "instância de proteção", ou até mesmo uma "possibilidade de 'recuperação e sustentação' de uma sociabilidade solidária".

À medida que o Estado se desresponsabiliza pela proteção social, a família é eleita como a detentora de tal, como espaço privilegiado de seus membros, e consequentemente, do bom andamento da sociedade. Há nesse discurso uma carga

\footnotetext{
${ }^{4}$ O Sistema de Garantia de Direitos é regido pela Resolução no 113, de 19 de Abril de 2006, do Conselho Nacional dos Direitos da Criança e do Adolescente (CONANDA) e preconiza que estebconstitui-se na articulação e integração das instâncias públicas governamentais e da sociedade civil, na aplicação de instrumentos normativos e no funcionamento dos mecanismos de promoção, defesa e controle para a efetivação dos direitos humanos da criança e do adolescente, nos níveis Federal, Estadual, Distrital e Municipal. Esse Sistema articular-se-á com todos os sistemas nacionais de operacionalização de políticas públicas, especialmente nas áreas da saúde, educação, assistência social, trabalho, segurança pública, planejamento, orçamentária, relações exteriores e promoção da igualdade e valorização da diversidade (BRASIL, 2006a).
} 
moral, bem como a culpabilização dos indivíduos por problemas e contextos que foram e são gerados socialmente.

Quando esta não tem condições de exercer o papel que lhe foi atribuído ela precisa ser trabalhada, inclusive através de políticas e programas sociais efetivos para que a criança e adolescente possam ser recebidos no ambiente familiar. Nos casos em que o acolhimento é necessário, o direito a convivência familiar deve ser assegurado, sendo criados mecanismos capazes de promovê-lo ou facilitá-lo.

\section{Convivência familiar}

A fim de um entendimento melhor da convivência familiar, faz-se necessário, primeiramente, compreender o conceito de família. Legalmente, a Constituição brasileira no Art. 226, parágrafo $4^{\circ}$ "entende como a entidade familiar a comunidade formada por

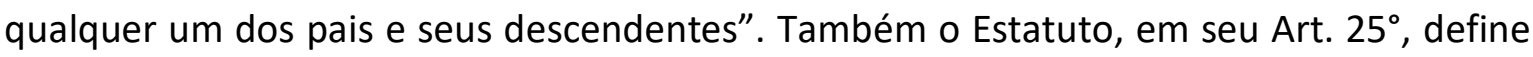
como família natural "entende-se por família extensa ou ampliada aquela que se estende para além da unidade pais e filhos ou da unidade do casal, formada por parentes próximos com os quais a criança ou adolescente convive e mantém vínculos de afinidade e afetividade".

Já o Sistema Único da Assistência Social (BRASIL, 2004) a define como “[...] um conjunto de pessoas que se acham unidas por laços consanguíneos, afetivos e, ou, de solidariedade." Estas definições colocam a ênfase na existência de vínculos de filiação legal, de origem natural ou adotiva, independentemente do tipo de arranjo familiar onde esta relação de parentalidade e filiação estiverem inseridas.

Entretanto, a definição legal não supre a necessidade de se compreender a complexidade e riqueza dos vínculos familiares e comunitários que podem ser mobilizados nas diversas frentes de defesa dos direitos de crianças e adolescentes. Falar em família pressupõe pensar as diferenciações por classe também, uma vez que o entendimento de família para o pobre não é o mesmo para a classe média.

Segundo Sarti (1995), a família para o pobre é definida como o conjunto de pessoas em quem se pode confiar, não havendo status ou poder a ser transmitido, o que vai definir a extensão da família é a rede de obrigações construídas, pois são da família 
aqueles com quem se pode contar, isto quer dizer, aqueles que retribuem ao que se dá, aqueles, portanto, para com quem se tem obrigações.

A família se define, assim, em torno de um eixo moral, onde a noção de obrigação sobrepõe-se à de parentesco. Conforme afirma Marcell Mauss (1974), não há relações com parentes de sangue se com eles não for possível dar, receber e retribuir, as três obrigações fundamentais que compõem este universo moral fundado no princípio da reciprocidade.

Logo, a família seria uma rede que se ramifica e envolve a gama de parentes e vizinhos, "configurando uma trama de obrigações morais que enreda os indivíduos em dois sentidos: ao dificultar sua individualização e ao viabilizar sua existência como apoio e sustentação básicos" (SARTI, 1995, p. 49).

Essa obrigação atrelada ao conceito de vínculo social relaciona-se diretamente com as redes, grupos ou indivíduos de quem se recebe proteção mediante as mais diversas necessidades, essa ideia é resumida pela autora nas expressões "ter com que e com quem contar", o que considera o conjunto de pessoas e/ou agentes dos serviços com quem os indivíduos podem receber auxílio nas mais diversas situações de necessidade.

Essa concepção considera as redes formadas por vizinhos, parentes, amigos, como parte do contexto de proteção, o que daria à família melhores condições de enfrentar a vulnerabilidade e o risco social. Dessa forma, o local onde a família está situada pode, ao considerar os vínculos sociais, oferecer maior ou menor grau de proteção,

\footnotetext{
A ideia de vínculos sociais associada à proteção social permite sintetizá-la na expressão "ter com que e com quem contar" face às agressões, fragilidades, aos riscos sociais e, mais do que isso, em ter segurança, ampliar o sentimento de certeza e de reconhecimento na construção da vida social. [...] A condição de "poder contar com" significa grau de solidez de um vínculo. [...] Os vínculos se estabelecem entre parentes, amigos, vizinhos, mas também, com agentes dos serviços gerando relações de certeza (SPOSATI, 2009, p.7).
}

Os vínculos são compreendidos enquanto laços carregados de obrigações mútuas que norteiam as relações entre os indivíduos. Essas obrigações se alteram dada a faixa etária, relações de status e gênero e definem o status da pessoa no contexto familiar. Dessa forma há uma diferença entre família como domicílio e família como rede de vínculo, nessa concepção são considerados os vínculos estabelecidos para além dos laços consanguíneos ou das relações de parentesco. 
Sob esse entendimento a família se torna o principal espaço de proteção dos indivíduos. As relações de cuidado e proteção vão além dos laços de consanguinidade, elas se estendem aos vizinhos, membros da família extensa entre outros.

É preciso considerar ainda as mudanças que vem ocorrendo no perfil das famílias e deve ser vista enquanto "um grupo social cujos movimentos de organizaçãodesorganização-reorganização mantêm estreita relação com o contexto sociocultural" (AFONSO; FILGUEIRAS, 1995).

Logo, a família nuclear tradicional, herança da família patriarcal brasileira, deixa de ser o modelo hegemônico e outras formas de organização familiar passam a ser reconhecidas, evidenciando que esta não é estática e que suas funções de proteção e socialização podem ser exercidas nos mais diversos arranjos familiares e contextos socioculturais, refutando qualquer ideia preconcebida de modelo familiar "normal".

Assim, o conceito de família "normal", "estruturada", passa pela desmistificação de uma estrutura única tida como ideal e, ainda, o deslocamento da ênfase da importância da estrutura familiar para suas funções de cuidado com a criança e com o adolescente, questionando a antiga concepção de "desestruturação familiar".

Ao longo dos anos essa instituição vem ganhando novos formatos, as relações entre seus membros passam a ter novas configurações. Essas transformações exigem novos olhares e interpretações em torno da família, não sendo hoje possível considerar a sua forma nuclear (pai, mãe e filhos), como única forma possível, ou idealiza-la como a única estrutura desejável para a formação da sociedade,

\footnotetext{
Aprendemos que as relações de parentesco são resultado da combinação de três relações básicas; a descendência entre pais e filhos, a consanguinidade entre irmãos e a afinidade a partir do casamento, sendo a família considerada como grupo social onde acontecem esses vínculos. Contudo, temos convivido com realidades diferenciadas que conformam a constituição desse fenômeno (família) para além das relações de parentesco. Pensar família hoje pressupõe seu entendimento enquanto um fenômeno que abrange as mais diferentes realidades (FREITAS; BRAGA; BARROS, 2011, p.17).
}

Essas transformações se dão pelo fato de a família não ser uma instituição desconecta da realidade social. Para que os indivíduos se reproduzam socialmente eles precisam anteriormente, se reproduzir como tais, o que ocorre, no contexto da família. 
Dessa forma ela acompanha e reflete as mudanças sociais, as ideias, a cultura a própria dinâmica da vida social como um todo.

No entanto, apesar das mudanças que ocorrem em sua estrutura, as famílias nucleares se isolam em seus próprios mundos. Os casais têm cada vez menos filhos e se tornam, nos termos de Ladislau Dowbor, "a família economicamente rentável", sob a égide do Capital o individualismo e consumismo altera os padrões de sociabilidade:

[...] O capitalismo moderno, centrado no consumismo, inventou a família economicamente rentável composta de mãe, pai e um casal de filhos, o apartamento, a geladeira para doze ovos, o sofá e a televisão. É a família nuclear (DOWBOR, 2010, p.294).

É importante ressaltar que uma das marcas trazidas pela industrialização ocorrida no Brasil nas primeiras décadas do século XX, foi a separação entre o público e o privado, fato que instituiu "a dimensão privada da família, contraposta ao mundo público" (SARTI, 2010). Mediante essa separação, a inserção das mulheres no mercado de trabalho e com os avanços tecnológicos, os formatos das famílias foram se alterando.

Essas mudanças ocorrem no âmbito de sua estrutura e formação, permanecendo intocadas às expectativas e funções atribuídas à família, sua capacidade protetiva em relação aos seus membros, continua sendo exigida, sendo, portanto, culpabilizados os indivíduos quando essa proteção não é oferecida, desconsiderando o caráter e as consequências trazidas pelas mudanças societárias no contexto da família. O que se pode ver é que:

[...] observa-se a permanência de velhos padrões e expectativas da família burguesa quanto ao seu funcionamento e desempenho de papéis paterno e materno, independente do lugar social que ocupam na estrutura de classes sociais (COUTO; YAZBEK; RAICHELIS, 2010, p. 55).

As famílias são responsabilizadas pelo sucesso e fracasso de seus membros, fato que pode ser visto com maior frequência em relação às crianças e adolescentes, que devido a fase de formação, necessitam de cuidado e proteção, sem levar em consideração, no entanto, que a capacidade protetiva dessa família passa pelas mudanças e contextos sociais em que está inserida, bem como, que há estruturas societárias que fogem ao controle individual ou familiar. 
Estudos realizados sobre a família, ou sobre a falta dela para crianças e adolescentes, a exemplo do trabalho de Szymanski (2002) com o título: Viver em família como experiência de cuidado mútuo: desafios de um mundo em mudança, e o de Prado (1986) sobre: O que é família. Contudo, faltam estudos mais consistentes sobre o impacto que a falta de vínculos familiares, comunitários, e de referências sociais, causam especificamente no adolescente.

Para Winnicott (2005), o ambiente familiar afetivo e continente às necessidades da criança e, mais tarde do adolescente, constitui a base para o desenvolvimento saudável ao longo de todo o ciclo vital. Tanto a imposição do limite, da autoridade e da realidade, quanto o cuidado e a afetividade são fundamentais para a constituição da subjetividade e desenvolvimento das habilidades necessárias à vida em comunidade.

Assim, as experiências vividas na família tornarão gradativamente a criança e o adolescente capazes de se sentirem amados, de cuidar, se preocupar e amar o outro, de se responsabilizar por suas próprias ações e sentimentos. Estas vivências são importantes para que se sintam aceitos também nos círculos cada vez mais amplos que passarão a integrar ao longo do desenvolvimento da socialização e da autonomia.

Entretanto, é preciso ampliar a compreensão das dificuldades que as famílias em situação de vulnerabilidade social passam para oferecer tal ambiente às suas crianças e adolescentes, visto suas necessidades de sobrevivência, as condições precárias de habitação, saúde e escolarização, a exposição constante aos ambientes de alta violência urbana, dentre outros fatores. Não é por acaso que se necessita de desenvolvimento de programas sociais voltados para as crianças e adolescentes em situação de vulnerabilidade social, quer tenham vínculos comunitários e familiares intactos, quer estejam em situação de afastamento provisório ou não de suas famílias.

\section{Convivência comunitária}

A partir da sua entrada na educação infantil ou no ensino fundamental, a criança expande seu núcleo de relacionamentos para além da família. Durante a infância e a adolescência o desenvolvimento é continuamente influenciado pelo contexto no qual a criança e o adolescente estão inseridos: 
A relação com colegas, professores, vizinhos e outras famílias, bem como da utilização das ruas, quadras, praças, escolas, igrejas, postos de saúde e outros, crianças e adolescentes interagem e formam seus próprios grupos de relacionamento. [...] Na relação com a comunidade, as instituições e os espaços sociais, eles se deparam com o coletivo - papéis sociais, regras, leis, valores, cultura, crenças e tradições, transmitidos de geração a geração - expressam sua individualidade e encontram importantes recursos para seu desenvolvimento (NASCIUTI, 1996, p. 100, 126).

Os espaços e as instituições sociais são, portanto, mediadores das relações que as crianças e os adolescentes estabelecem, contribuindo para a construção de relações afetivas e de suas identidades individual e coletiva. Nessa direção, se o afastamento do convívio familiar for necessário, as crianças e adolescentes devem, na medida do possível, permanecer no contexto social que Ihes é familiar. Além de muito importante para o desenvolvimento pessoal, a convivência comunitária favorável contribui para o fortalecimento dos vínculos familiares e a inserção social da família.

Nesse sentido, Takashima (2004) destaca que algumas estratégias da comunidade contribuem para a proteção da criança e do adolescente, constituindo formas de apoio coletivo entre famílias em situação de vulnerabilidade social: redes espontâneas de solidariedade entre vizinhos: a família recebe apoio em situações de crise como morte, incêndio ou doenças; práticas informais organizadas: a comunidade compartilha com os pais ou responsáveis a função de cuidado com a criança e com o adolescente, bem como denuncia situações de violação de direitos, dentre outras; e práticas formalmente organizadas: a comunidade organiza projetos e cooperativas para a geração de emprego e renda, por exemplo.

Pereira e Costa (2004), em O ciclo recursivo do abandono, estudaram o acolhimento institucional, e observaram que as famílias de crianças e adolescentes abrigados geralmente não possuem rede familiar extensa ou redes sociais de apoio na comunidade. As autoras apontam que estas famílias, predominantemente monoparentais e chefiadas pela mulher, possuem uma história marcada pela exclusão social, migração e ruptura de vínculos afetivos.

Vivências de "desenraizamento familiar e social" associam-se à falta de um grupo familiar extenso e de vínculos significativos na comunidade aos quais a família possa recorrer para encontrar apoio ao desempenho de suas funções de cuidado e proteção à criança e ao adolescente. Para as referidas autoras: 


\begin{abstract}
Além da influência que o contexto exerce sobre o desenvolvimento da criança e do adolescente, as redes sociais de apoio e os vínculos comunitários podem favorecer a preservação e o fortalecimento dos vínculos familiares, bem como a proteção e o cuidado à criança e ao adolescente. Além de potencial para o desenvolvimento da criança, do adolescente e da família é na utilização dos espaços e instituições sociais e nas relações socialmente estabelecidas que direitos são também violados (PEREIRA; COSTA, 2004, p. 40).
\end{abstract}

As famílias também podem estar particularmente expostas às tensões externas que fragilizam seus vínculos, tornando-as mais vulneráveis. A violência, a discriminação, o consumismo veiculado na mídia, a intolerância e a falta de acesso às políticas sociais básicas - aspectos, relacionados à própria estruturação da sociedade brasileira - acabam repercutindo sobre a possibilidade de uma convivência familiar e comunitária saudável.

Nesse sentido, Szymanski (2002) relembra que a violência é responsável pela maior parte das mortes entre jovens das camadas mais empobrecidas da população. A autora afirma que a violência urbana, fortemente associada ao tráfico e ao consumo de drogas, tem reflexos na vida das famílias das diferentes classes sociais repercutindo sobre as relações intrafamiliares, no desenvolvimento de seus membros e na relação com o contexto social.

Assim, é possível afirmar, conforme destacado por Vicente (2000), que os vínculos familiares e comunitários possuem uma dimensão política, na medida em que tanto a construção quanto o fortalecimento dos mesmos dependem também, dentre outros fatores, de investimento do Estado em políticas públicas voltadas à família, à comunidade e ao espaço coletivo - habitação, saúde, trabalho, segurança, educação, assistência social, desenvolvimento urbano, combate à violência, ao abuso e à exploração de crianças e adolescentes, distribuição de renda e diminuição da desigualdade social, meio ambiente, esporte e cultura, dentre outros.

\title{
O plano nacional de promoção proteção e defesa do direito de crianças e
}

\section{adolescentes à convivência familiar e comunitária}

Com a promulgação da Constituição Federal, em 1988, do Estatuto da Criança e do Adolescente, em 1990, da Lei Orgânica da Assistência Social, em 1993, e com a ratificação da Convenção sobre os Direitos da Criança em 1990, temos uma mudança no cenário 
nacional que provoca rupturas em relação às concepções e práticas assistencialistas e institucionalizantes.

A legislação brasileira vigente reconhece e preconiza a família enquanto estrutura vital, lugar essencial à humanização e à socialização da criança e do adolescente, espaço ideal e privilegiado para o desenvolvimento integral dos indivíduos. Contudo, a história social das crianças, dos adolescentes e das famílias, apresentada no início deste texto, revela que estas encontraram e ainda encontram inúmeras dificuldades para proteger e educar seus filhos. Dificuldades que foram traduzidas pelo Estado em um discurso sobre a pretensa "incapacidade" da família de orientar os seus filhos, que subsidiou suas ações de institucionalização de crianças e adolescentes de baixa renda ao longo de vários anos.

Diante desse cenário de mudanças na legislação e de paradigmas, em 2002, foi realizado no Brasil um Colóquio Técnico sobre Rede Nacional de Abrigos, que contou com a participação de entidades governamentais e não governamentais dos diferentes estados. Nesse evento foram identificadas ações a serem priorizadas, entre elas: a realização de um censo nacional de crianças e adolescentes em abrigos e práticas institucionais, e a elaboração de um plano de ação para o seu reordenamento. Para continuação desse processo foi criado um Comitê Nacional para o reordenamento dos abrigos, que tinha por objetivo estimular mudanças nas políticas e práticas de atendimento, para a efetivação do que preconiza o Estatuto a respeito do direito de crianças e adolescentes à convivência familiar e comunitária.

No início de 2004, o Conselho Nacional dos Direitos da Criança e do Adolescente (CONANDA) elegeu como uma de suas prioridades a promoção do direito de crianças e adolescentes à convivência familiar e comunitária. O Ministro Chefe da Secretaria Especial dos Direitos Humanos e o Ministro de Estado de Desenvolvimento Social e Combate à Fome se articularam e propuseram a convocação de outros Ministérios e atores nesse movimento. Assim, com essa maior integração intersetorial, ampliou-se o escopo temático para além da proposta inicial de reordenamento dos abrigos, incorporando questões sobre família e adoção. Com isso, a Comissão Intersetorial do Comitê Nacional, teve por finalidade superior construir subsídios à elaboração do Plano Nacional de Promoção, Proteção e Defesa do Direito de Crianças e Adolescentes à Convivência Familiar e Comunitária (PNCFC). 
Portanto, com vistas a uma política de promoção, proteção e defesa do direito da criança e do adolescente à convivência familiar e comunitária, em 2006, a Presidência da República, a Secretaria Especial dos Direitos Humanos, o Ministério do Desenvolvimento Social e Combate à Fome, o CONANDA, o Conselho Nacional da Assistência Social (CNAS), com apoio do UNICEF, lançaram o PNCFC (BRASIL, 2006), produto histórico da elaboração de inúmeros atores sociais comprometidos com os direitos das crianças e adolescentes brasileiros. Essa ação acontece simultaneamente ao processo de discussão internacional liderado pelo Comitê dos Direitos da Criança da Organização da Organização das Nações Unidas (ONU) sobre a necessidade de aprimorar os mecanismos de proteção integral dos direitos da criança privada dos cuidados parentais.

Como objetivo o Plano espera contribuir para a construção de um novo patamar conceitual que orientará a formulação das políticas para que cada vez mais crianças e adolescentes tenham seus direitos assegurados e encontrem na família os elementos necessários para seu pleno desenvolvimento. Novas possibilidades, recursos e habilidades são desenvolvidos frente aos desafios que se interpõem em cada etapa de seu ciclo de desenvolvimento e, como seus membros, ela está em constante evolução: seus papéis e organização estão em contínua transformação.

Desse modo, esse ponto é de fundamental importância para se compreender o investimento no fortalecimento e no resgate dos vínculos familiares em situação de vulnerabilidade, pois cada família, dentro de sua singularidade, é potencialmente capaz de se reorganizar diante de suas dificuldades e desafios, de maximizar as suas capacidades, de transformar suas crenças e práticas para consolidar novas formas de relações. Porém, o fortalecimento da família deve ser apoiado e maximizado por políticas de apoio sociofamiliar, em diferentes dimensões, que visem à reorganização do complexo sistema de relações familiares, especialmente no que se refere ao respeito aos direitos de crianças e adolescentes.

Para tanto, a efetivação desse direito envolve o esforço de toda a sociedade e o compromisso com uma mudança cultural que atinge as relações familiares, as relações comunitárias e as relações do Estado com a sociedade. A concretização do direito só será garantida com a interação de todas as políticas sociais, com centralidade na família para o acesso a serviços de saúde, educação de qualidade, geração de emprego e renda, entre 
outras. Dessa forma, as contribuições sobre o papel de cada setor no apoio e garantia dele será de grande relevância.

Contudo, apesar do Plano corroborar à necessidade de efetivação do direito à convivência familiar e comunitária para todas as crianças e adolescentes, ele faz um corte em três eixos principais: em primeiro lugar, a família de origem e a comunidade na qual está inserida, a importância da preservação dos vínculos familiares e comunitários e o papel das políticas públicas de apoio sociofamiliar; em segundo lugar, a intervenção institucional nas situações de rompimento ou ameaça de rompimento dos vínculos familiares e no investimento no reordenamento dos programas de Acolhimento Institucional e na implementação dos Programas de Famílias Acolhedoras ${ }^{5}$, com ênfase na excepcionalidade e na provisoriedade destas medidas e, ainda, na preservação, fortalecimento e restauração dos vínculos familiares; por fim, em terceiro lugar, a necessidade de uma nova família para a criança e para o adolescente que perdeu a sua própria.

Historicamente essas instituições, abrigos, orfanatos, casas-lares, tinham o objetivo de prevenir ou tratar atitudes ou situações de "desvio" individual e social, o que resultava na institucionalização e na quebra dos vínculos familiares e comunitários. Sob a perspectiva da proteção integral, esses programas e instituições passam a ter um novo foco de ação, diante das condições de vulnerabilidade apresentadas pelas famílias.

Desta forma, o Plano denota a pertinência da convivência familiar, enquanto direito, e estabelece ações e prazos específicos para sua efetivação. Com certeza, representa um avanço no reconhecimento da criança e do adolescente como sujeitos de direitos. No entanto, reconhece que:

[...] A defesa desse direito dependerá do desenvolvimento de ações intersetoriais, amplas e coordenadas que envolvam todos os níveis de proteção social e busquem promover uma mudança não apenas nas condições de vida, mas também nas relações familiares e na cultura brasileira para o

\footnotetext{
5 Segundo o PNCFC (BRASIL, 2006), o Programa de Famílias Acolhedoras caracteriza-se como um serviço que organiza o acolhimento, na residência de famílias acolhedoras, de crianças e adolescentes afastados da família de origem mediante medida protetiva. Representa uma modalidade de atendimento que visa oferecer proteção integral às crianças e aos adolescentes até que seja possível à reintegração familiar. Ressalta-se que este Programa não deve ser confundido com a adoção. Trata-se de um serviço de acolhimento provisório, até que seja viabilizada uma solução de caráter permanente para a criança ou adolescente - reintegração familiar ou, excepcionalmente, adoção.
} 
reconhecimento das crianças e adolescentes como pessoas em desenvolvimento e sujeitos de direitos (BRASIL, 2006, p.67).

Assim, a materialização do Plano acontece de forma conjunta, coletiva e intersetorial, tendo em vista que prevê a participação das três esferas de governo e institui atribuições e competências, específicas a cada esfera. Suas ações estão organizadas em quatro eixos estratégicos a análise da situação e sistemas de informação, atendimento, marcos normativos e regulatórios e a mobilização, articulação e participação.

O Plano propõe uma mudança no tocante à proposta de atendimento de crianças e adolescentes, substituindo o modelo do abrigamento e da institucionalização pelo "novo paradigma que elege a família como unidade básica da ação social e não mais concebe a criança e o adolescente isolados de seu contexto familiar e comunitário" (BRASIL, 2006, p.67).

O reordenamento das instituições de acolhimento e os programas criados no sentido de devolver a criança e ao adolescente o convívio familiar e comunitário (como o Programa de Famílias Acolhedoras e de Adoção), que está previsto no Plano, se configura como mecanismos de transformação da situação de crianças e adolescentes, cujos vínculos familiares estejam fragilizados ou tenham sido quebrados, diante das condições de vulnerabilidade social a que foram expostos.

Vale ressaltar que em consonância com as mudanças previstas no PNCFC, foi aprovada, em agosto de 2009, a Lei 12.010 que altera alguns artigos do Estatuto da Criança e do Adolescente e dispõe sobre normas que regulamentam o processo de adoção, assim como preconiza mudanças no atendimento a crianças e adolescentes em instituições de acolhimento com o objetivo de promover a garantia do direito à convivência familiar. O seu primeiro artigo explicita o objetivo para qual foi criada:

Art. $1^{\circ}$ Esta Lei dispõe sobre o aperfeiçoamento da sistemática prevista para garantia do direito à convivência familiar a todas as crianças e adolescentes, na forma prevista pela Lei no 8.069, de 13 de julho de 1990, Estatuto da Criança e do Adolescente (BRASIL, 2009, p.01).

Segundo seus artigos, a situação de cada criança/adolescente deve ser revista pela autoridade judiciária a cada seis meses, mediante relatório emitido pela equipe 
interdisciplinar da instituição de acolhimento, decidindo pela reintegração familiar ou colocação em família substituta. Essa lei também estipula um prazo limite para o período de acolhimento, no máximo dois anos, com exceção de casos em que seja necessário um período maior, mediante autorização judiciária.

Essa nova determinação exige das instituições que formam a rede de proteção à criança e ao adolescente uma mudança de metodologia de ação que vise promover à desinstitucionalização em um tempo menor, fato que ratifica a disposição do Estatuto de que o acolhimento é uma medida excepcional e provisória, que não implica em privação de liberdade.

Não se trata apenas da execução da letra da lei ou do alcance de metas e prazos estabelecidos, nem tão pouco de afiançar a qualidade dos programas de acolhimento. Diz respeito à necessidade do trabalho social intensivo com as famílias que irão receber os acolhidos, da garantia dos direitos sociais, do trabalho intersetorial, da efetivação da proteção social, enquanto dever do Estado. Nesse sentido, o processo de fortalecimento da família, com vistas à reintegração familiar antecede qualquer outra providência a ser tomada em relação à criança/adolescente, conforme versa o Art. 19, parágrafo terceiro da referida lei:

$\S 3^{\circ} \mathrm{A}$ manutenção ou reintegração de criança ou adolescente à sua família terá preferência em relação a qualquer outra providência, caso em que será esta incluída em programas de orientação e auxílio, nos termos do parágrafo único do art. 23, dos incisos I e IV do caput do art. 101 e dos incisos I a IV do caput do art. 129 desta Lei. (BRASIL, 2010, p.14).

A Lei atribui à família centralidade no trato e cuidado de crianças e adolescentes em situação de acolhimento, confirmando o que tem sido preconizado pela Constituição Federal, pelo Estatuto e por leis como Lei Orgânica de Assistência Social e a Política Nacional de Assistência Social. É importante ressaltar que para esses artigos da lei serem efetivados, a rede de proteção deve estar articulada, uma vez que, tratam-se de vínculos fragilizados e/ou perdidos com essas famílias dado o contexto de violação de direitos a que foram submetidos.

Deve ser levado em consideração o bem-estar da criança ou do adolescente, atendendo, quando este for capaz de opinar, o seu desejo, fazendo valer o papel de sujeito de direitos ressaltado pelo Estatuto, assim como, criando mecanismos para a afirmação de sua autonomia, e principalmente, a desinstitucionalização. 
O Estatuto representou um marco para o reordenamento das instituições que acolhiam crianças e adolescentes em situação de risco mediante a perda de vínculos familiares. O aperfeiçoamento trazido pela Lei 12.010 contribui para a efetivação e manutenção desse reordenamento.

Essas mudanças exigem um esforço de toda a rede de proteção e em especial das instituições de acolhimento, no sentido de fazer valer a excepcionalidade e provisoriedade do atendimento, e na criação e efetivação de ações que viabilizem a reinserção familiar e torne as instituições de acolhimento espaços de curta permanência, espaços de proteção e garantia de direitos, e antes de tudo, espaços que promovam a convivência familiar, espaços de liberdade.

O prazo estabelecido pela nova lei (no máximo dois anos) para o período de acolhimento aponta um novo norte para crianças e adolescentes em medida protetiva de abrigo, exigindo que as instituições se articulem e tracem um plano efetivo para que a institucionalização seja de fato provisória,

\footnotetext{
Entretanto, no universo de entidades de acolhimento institucional pesquisado, o percentual de crianças e adolescentes que permaneceram no serviço até o período de seis meses não chega a $20 \%$. Em torno de $50 \%$ dos atendidos permanecem no serviço entre 6 meses a 2 anos e um número bastante alto, correspondente a aproximadamente $35 \%$ dos acolhidos, são mantidos nas entidades por mais de dois anos, o que corresponde a mais de 10 mil crianças e adolescentes (CONSELHO NACIONAL DO MINISTÉRIO PÚBLICO, 2013, p.52).
}

Mesmo diante das mudanças e avanços legislativos, o tempo de permanência nas instituições permanece alto, o que pode ser explicado, em parte, pela dificuldade da superação do contexto que condicionou o acolhimento institucional.

O desligamento deve ocorrer de forma gradativa, e nesse processo o trabalho social envolvendo a família é primordial para essa superação. A medida de acolhimento, embora seja necessária, não pode ser a única atitude protetiva, essa deve ser acompanhada do acionamento da rede de proteção para que o retorno da criança/adolescente alcance resultado satisfatório, caso contrário, o acolhimento pode perdurar e, ainda assim, a reintegração familiar não ocorrer de forma exitosa.

Entretanto o aumento do número de crianças e adolescentes acolhidos no país nos últimos anos demonstra que ainda há muito a ser feito. A diminuição do número de atendimentos por unidade de acolhimento levou ao aumento do número de Unidades, 
uma vez que, embora tenham ocorrido significativos avanços na qualidade do atendimento, as causas não são facilmente combatidas.

Segundo dados do Ministério Público existem atualmente 2.598 unidades de acolhimento institucional e 2.754 unidades de acolhimento familiar em todo o País, que atendem juntamente mais de 30.000 crianças e adolescentes.

Em 2004, havia cerca de 20 mil crianças e adolescentes vivendo nos 589 abrigos pesquisados em todo o Brasil, segundo o IPEA (SILVA, 2004), em pesquisa realizada pelo "Levantamento Nacional de Abrigos para Crianças e Adolescentes da Rede SAC". Os dados indicaram também que ocorreu nos últimos oito anos o crescimento do número de acolhidos no País, mesmo diante dos avanços legais e esforços para a diminuição do acolhimento institucional e familiar. A região Nordeste contava com 228 Unidades, que segundo o relatório, possuía capacidade de atender 5.549 crianças e adolescentes. O estado da Paraíba contava com 19 Unidades de Acolhimento Institucional, com capacidade de atendimento para 290 crianças e adolescentes, estando acolhidas no momento da pesquisa, 249.

O município de João Pessoa (PB) conta atualmente com 10 instituições de acolhimento: Lar da Criança Shalom, Missão Restauração, Abrigo Institucional Morada do Betinho, Abrigo Institucional Manaíra, Lar da Criança Jesus de Nazaré, Aldeias SOS da Paraíba, Casa de Acolhida Masculina, Casa de Acolhida Feminina, Casa de Passagem e Casa Padre Pio de Pietrelcina.

Segundo pesquisa realizada nos anos de 2005/2007 pelo Setor de Estudos e Pesquisas em Análise de Conjuntura (SEPACOPS) em parceria com Rede Margarida de Proteção à Criança e ao Adolescente (REMAR), o Município contava com 17 unidades existentes na época da pesquisa, onde havia 609 vagas com um total de 487 acolhidos, o que correspondia a $80 \%$ da ocupação das vagas.

Conforme o IPEA (SILVA, 2004) entre os principais motivos do acolhimento das crianças e dos adolescentes estão: a carência de recursos materiais da família (24,1\%); o abandono pelos pais ou responsáveis (18,8\%); a violência doméstica (11,6\%); a dependência química de pais ou responsáveis (11,3\%); a vivência de rua $(7,0 \%)$; a orfandade (5,2\%); a prisão dos pais ou responsáveis $(3,5 \%)$ e o abuso sexual praticado pelos pais ou responsáveis (3,3\%). 
Em consonância com esses dados, o relatório do Ministério Público mostrou que os principais motivos para o acolhimento institucional em 2012 e 2013 são:

\begin{abstract}
Negligência dos pais e/ou responsável (mais de 80\%); Dependência química/alcoolismo dos pais e/ou responsável; (mais de 80\%); Abandono dos pais e/ou responsável (em torno de 77\%); Violência doméstica; (próximo a $60 \%$ ); Abuso sexual praticado pelos pais e/ou responsável (em torno de $45 \%$ ) (CONSELHO NACIONAL DO MINISTÉRIO PÚBLICO, 2013, p.43).
\end{abstract}

Os dados percentuais do Conselho Nacional do Ministério Público, aqui apresentados, agregam os motivos das duas modalidades de acolhimento institucionais pesquisadas, abrigo e casa lar, não sendo destacado apenas o principal como nas outras pesquisas, por isso são valores aproximados que estabelecem um ranking com as principais causas para acolhimento institucional.

Quanto aos motivos que causaram o acolhimento institucional, em João Pessoa/PB, segundo Almeida, Neves e Xavier (2008), foi apontado: a carência de recursos materiais $23,8 \%$, abandono pelos pais e responsáveis $19,5 \%$, violência doméstica $10,1 \%$, pais ou responsáveis sem condições de cuidar de crianças com câncer 9,7\%, vivência na rua 6,8\%, ausência dos pais ou responsáveis por doença $4,1 \%$, órfão $4,1 \%$, pais ou responsáveis dependentes químicos 3,9\%, pais ou responsáveis detidos 3,5\%, exploração sexual $2,5 \%$, pais ou responsáveis portadores de deficiência 2,3\%, exploração no trabalho 2,1\%, abuso sexual praticado pelos pais ou responsáveis $1,4 \%$, entre outros fatores.

Os dados de ambas as pesquisas demonstram que os motivos que causaram 0 acolhimento pouco se alteraram, estando ligados à violação de direitos quer seja pela ação/omissão do Estado, da sociedade ou da família como prevê o Estatuto. Destaca-se o crescimento considerável da dependência química e a diminuição da quantidade de casos aonde a ausência de recursos financeiros como motivo para a medida de proteção,

Com base na constatação dos motivos que levam ao acolhimento, pode-se dizer que a violação de direitos básicos, em geral por parte do poder público, destaca-se como gerador da inclusão das crianças, adolescentes e famílias pobres no sistema de Justiça. O abrigo é, na verdade, o espaço no qual são canalizadas as situações resultantes das faltas e das omissões originadas por muitos. Entretanto, oscilamos em responsabilizar um polo ou outro desse sistema - o Judiciário, o Executivo, os abrigos, o Ministério público e, especialmente, as próprias famílias - pela situação provisória do acolhimento. Com isso, deixa-se de construir estratégias de acordo com a realidade da rede de atendimento local, as quais pressupõem compartilhar a missão do desacolhimento e da reintegração familiar (OLIVEIRA, 2006, p. 47). 
Os motivos que conduzem ao acolhimento estão ligados diretamente às situações de violação de direitos, que podem ser atreladas ao contexto de desproteção a que estão submetidas às famílias. A medida de acolhimento tem caráter provisório, no entanto, as ações no sentido de reinserir as crianças e adolescentes, devem ter caráter permanente, caso contrário, não é possível considerar a convivência familiar e comunitária enquanto direito.

A convivência familiar e comunitária é o direito assegurado às crianças e adolescentes de serem cuidados por uma família, dentro de uma comunidade, quer seja sua família de origem ou substituta. Rizzini entende a convivência familiar como:

[...] a possibilidade da criança permanecer no meio a que pertence. De preferência junto à sua família, ou seja, seus pais e/ou outros familiares. Ou, caso isso não seja possível, em outra família que a possa acolher. Assim, para os casos em que há necessidade das crianças serem afastadas provisoriamente de seu meio, qualquer que seja a forma de acolhimento possível, deve ser priorizada a reintegração ou reinserção familiar - mesmo que este acolhimento tenha que ser institucional (RIZZINI, 2007, p.22).

O Estatuto coloca o acolhimento institucional como uma medida protetiva que só deve ser aplicada quando esgotadas todas as possibilidades de manutenção dos vínculos familiares, ou quando o ambiente familiar se constitui ameaça ao desenvolvimento e bem estar da criança e adolescente.

A família tem ganhado centralidade dentro das políticas públicas, sendo ela reconhecida como a responsável pelo cuidado e bem-estar de seus membros. Quando esta não tem condições de exercer o papel que Ihe foi atribuído ela precisa ser auxiliada, inclusive através de políticas e programas sociais efetivos para que a criança e adolescente possam ser recebidos no ambiente familiar. Nos casos em que o acolhimento é necessário, o direito a convivência familiar deve ser assegurado, sendo criados mecanismos capazes de promovê-lo ou facilitá-lo.

Visitas dos familiares nas instituições, e da criança à família (desde que essas sejam devidamente autorizadas e sem representar risco para a criança) são estratégias para a garantia de que as crianças institucionalizadas tenham contato direto com a comunidade em que estão inseridos, entre outras formas.

Conforme a pesquisa realizada por Almeida, Neves e Xavier (2008), as instituições promoviam ações de convivência das crianças com as famílias de origem, dentre as que 
foram citadas estão a promoção de visitas das crianças e adolescentes aos lares das famílias $(70,6 \%)$, ou ainda permitir a visita na instituição das famílias e manter unidos grupos de irmãos (52,9\%). Essas ações incentivam e até contribuem para o processo de reintegração familiar.

No entanto, a pesquisa realizada pelo Ministério Público apontou que nos últimos dois meses de 2012 , apenas $24 \%$ dos acolhidos em abrigos institucionais recebiam visitas, esse percentual caiu, em 2013, para 23\%. Nas Casas Lares esse percentual é de 24,4\% e $23,5 \%$ respectivamente.

Na região Nordeste o percentual é de apenas $24 \%$ nos abrigos e $21 \%$ nas Casas Lares no ano de 2013. A ausência de visitas frequentes retrata o persistente contexto de abandono e a necessidade da atuação das equipes das instituições as famílias de origem, sensibilizando quanto à necessidade das visitas, identificando os motivos pelos quais elas não ocorrem e auxiliando à família a saná-los. Essa realidade se configura em uma dificuldade na garantia do direito à convivência familiar.

Esse direito deve ser assegurado não apenas pelas instituições responsáveis pelo acolhimento, como também pelos órgãos que compõem a rede de proteção, que inclui o poder Judiciário (Juizado e Curadoria da Infância e Juventude), os Conselhos Tutelares, o poder Executivo nas três esferas - federal, estadual e municipal.

A ineficiência das políticas públicas em um contexto de diminuição de investimentos na área social, somado a desproteção social a que estão submetidas às famílias, causam situações de violação de direitos que o avanço legal e normativo não é, sozinho, capaz de resolver. O investimento em serviços de caráter universal, em programas de proteção social, pode ser considerado o início das respostas que precisam ser dadas pelo Estado para a alteração dessa conjuntura.

\section{Considerações finais}

Os avanços legais e normativos no sentido de garantir o direito à convivência familiar e comunitária são notórios, todos os mecanismos e legislações criados nesse sentido são de fato um avanço, principalmente se considerarmos o contexto a que, historicamente, foram submetidas às crianças e adolescentes, alvos de políticas ora repressoras, ora caritativas. 
No entanto, apenas marcos normativos não são suficientes para a efetivação de um direito, é necessário a ação do Estado por meio de políticas públicas que deem às famílias a proteção necessária para que elas cuidem dos seus membros. A garantia da convivência familiar e comunitária implica na garantia de outros direitos, também subscritos em lei: saúde, educação, moradia entre outros. Sem essas garantias o direito à convivência familiar e comunitária não passará de um discurso, vazio de significado e efetivação.

Fica clara a necessidade de que as políticas de proteção social estejam voltadas para a família como um todo, e não com enfoque apenas em um ou outro membro, bem como, que suas ações ocorram de fato com caráter de proteção integral. O potencial protetivo das famílias depende da atuação de políticas que efetivem os direitos socialmente conquistados.

Faz-se necessário, então, o investimento na família e a garantia dos direitos para que esta possa desenvolver sua capacidade protetiva para com seus membros, e assim se configure como um ambiente saudável para o desenvolvimento de crianças e adolescentes, como preconiza o Estatuto.

Por outro lado, sabe-se que as iniciativas e esforços para mudanças eficazes e estruturais no sentido de efetivação dos direitos sociais, incluindo o direito à convivência familiar e comunitária, não partirão apenas dos órgãos gestores. É preciso o protagonismo político dos profissionais que executam a política, dos usuários da Assistência Social, e dos demais atores que compõe o Sistema de Garantia de Direitos, no sentido de fortalecer os espaços de reinvindicação, debate e luta, para que dessa forma os direitos, garantidos legalmente, sejam afiançados e a proteção integral efetivada.

\section{Referências}

AFONSO, M. L. M.; FILGUEIRAS, C. A. C. A centralidade da figura materna nas políticas sociais dirigidas a famílias: um argumento pela equidade. In: ENCONTRO ANUAL DA ANPOCS, 21., 1995, Caxambu.

ALMEIDA, B. L. F.; NEVES, M. E. R.; XAVIER, S. A. A. Realidade dos Abrigos para Crianças e adolescentes de João Pessoa/ PB: desafios e perspectivas. 2. ed. Recife: Gráfica Brascolor, Editora Universitária da UFPB, 2008. 
BRASIL. Constituição (1988). Constituição da República Federativa do Brasil. Brasília, DF, 1988. Disponível em: <http://www.planalto.gov.br/ccivil_03/constituicao/constitui\% C3\%A7ao.htm>. Acesso em: 12 jan. 2016.

. Conselho Nacional dos Direitos da Criança e do Adolescente. Plano Nacional de Promoção. Proteção e Defesa do Direito de Criança e Adolescente à Convivência Familiar e Comunitária. Brasília: CONANDA, 2006.

. Conselho Nacional dos Direitos da Criança e do Adolescente. Resolução 113, de 19 de abril de 2006. Brasília: CONANDA, 2006a. Disponível em: <http://dh.sdh.gov.br/ download/resolucoes-conanda/res-113.pdfm>. Acesso em: 12 jan. 2016.

Lei n. 12.010 , de 3 de agosto de 2009. Dispõe sobre adoção; altera as Leis nos 8.069, de 13 de julho de 1990 - Estatuto da Criança e do Adolescente, [...] e dá outras providências. Brasília, 2009. Disponível em: <http://www.planalto.gov.br/ccivil_03/ _ato2007-2010/2009/lei/l12010.htm>. Acesso em: 12 jan. 2016.

Lei n. 8.742, de 7 de dezembro de 2003. Lei Orgânica da Assistência Social LOAS. Dispõe sobre a organização da Assistência Social e dá outras providências. Brasília, 1993. Disponível em: <http://www.planalto.gov.br/ccivil_03/Leis/L8742.htm>. Acesso em: 12 jan. 2016.

Ministério do Desenvolvimento Social e Combate à Fome. Política Nacional de Assistência Social - PNAS/ 2004. Brasília, 2004.

. Secretaria Especial dos Direitos Humanos. Estatuto da Criança e do Adolescente. Brasília, 2010.

CONSELHO NACIONAL DO MINISTÉRIO PÚBLICO. Um olhar mais atento aos serviços de acolhimento de crianças e adolescentes no país: Relatório da Resolução n71/2011.

Brasília, 2013.

COUTO, B. R.; YAZBEK, M. C.; RAICHELIS, R. A Política Nacional de Assistência Social e o Suas: apresentando e problematizando fundamentos e conceitos. In: COUTO, B. R. et al. O Sistema Único de Assistência Social no Brasil: uma realidade em movimento. São Paulo: Cortez, 2010.

DOWBOR, L. A economia da família. In: ACOSTA, A. R.; VITALE, M. A. F. (Org.). Família Redes, Laços e Políticas Públicas. 5. ed. São Paulo: Cortez: Coordenadoria de Estudos e Desenvolvimento de Projetos Especiais - PUC- SP, 2010.

FREITAS, R. C. S.; BRAGA, C. D.; BARROS, N. V. Famílias e Serviço Social: Algumas Reflexões para o Debate. In: DUARTE, M. J. O.; ALENCAR, M. M. T. (Org.). Família Famílias: práticas sociais e contemporâneas. 2ed. Rio de Janeiro: Lumen Juris, 2011.

SILVA. E. R. A. (Coord.). O direito à convivência familiar e comunitária: os abrigos para crianças e adolescentes no Brasil. Brasília: IPEA/CONANDA, 2004. 
MIOTO, R. C. Familia e Políticas Sociais. In: BOSCHETTI, I. et al. (Org.). Política Social no Capitalismo: tendências contemporâneas. 2. ed. São Paulo: Cortez, 2009.

MAUSS, M. Ensaio sobre a dádiva: forma e razão da troca nas sociedades arcaicas. In: . Sociologia e antropologia. São Paulo: E.P.U; EDUSP. 1974. v. 2, p. 37-184.

NASCIUTI, J. R. A instituição como via de acesso à comunidade. In: CAMPOS, R. H. F. (Org). Psicologia social e comunitária: Da solidariedade à autonomia. Rio de Janeiro: Vozes, 1996. p. 100-126.

OLIVEIRA, Rita de Cássia. A história começa a ser revelada: panorama atual do abrigamento no Brasil. IN: Abrigo: Comunidade de Acolhida e socioeducação. Baptista, Myrian Veras (coord.). São Paulo: Instituto Camargo Corrêa, 2006. (Coletânea abrigar: 1).

PEREIRA, J. M. F.; COSTA, L. F. O ciclo recursivo do abandono. Psicologia.Pt, 2004 Disponível em: <http://www.psicologia.com.pt/artigos/ver_artigo.php?codigo=A0207\& area $=\mathrm{d} 4 \&$ subarea=>. Acesso em: 29 out. 2006.

PRADO, D. O que é família. 8. ed. São Paulo: Brasiliense, 1986.

RIZZINI, I. Reflexões sobre o Direito à Convivência Familiar e Comunitária de Crianças e Adolescentes no Brasil. 2006. Disponível em: <http://www.sbp.com.br/show_item.cfm? id_categoria=74\&id_detalhe=1354\&tipo=D>. Acesso em: 14 jan 2016.

RIZZINI, I. (Coord.). Acolhendo crianças e adolescentes: experiências de promoção do direito à convivência familiar e comunitária no Brasil. 2 ed. São Paulo: Cortez, 2007.

SARTI, C. A. O valor da família para os pobres. In: RIBEIRO, I.; RIBEIRO, A. C. T. (Org.). Família em processos contemporâneos: inovações culturais na sociedade brasileira. São Paulo: Loyola, 1995. p. 131-150.

SARTI, C. A. Famílias enredadas. In: ACOSTA, Ana Rojas; VITALE, Maria Amalia Faller. (Org.). Família: redes, laços e politicas públicas. 5. ed. São Paulo: Cortez: Coordenadoria de Estudos e Desenvolvimento de Projetos Especiais - PUC, 2010.

SPOSATI, A. Modelo brasileiro de proteção social não contributiva: concepções fundantes. In: BRASIL. Ministério do Desenvolvimento Social e Combate à Fome. Concepção e gestão da proteção social não contributiva no Brasil. Brasília, UNESCO, 2009. p. 13-56.

SZYMANSKI, H. Viver em família como experiência de cuidado mútuo: desafios de um mundo em mudança. Revista Serviço Social \& Sociedade, São Paulo, ano 23, n. 71, p. 9-25, 2002.

TAKASHIMA, G. M. K. O Desafio da Política de Atendimento à Família: dar vida às leis uma questão de postura. In: KALOUSTIAN, S. M. (Org.). Família Brasileira: a base de tudo. São Paulo: Cortez, Brasília: UNICEF, 2004. 
VICENTE, M.C. O direito a convivência familiar e comunitária: uma política de manutenção de vínculo. In: KALOUSTIAN, S.M. (Org.). Família brasileira, a base de tudo. 4. ed. São Paulo: Unicef/Cortez, 2000. p. 47-59.

WINNICOTT D. W. A família e o desenvolvimento individual. São Paulo: Martins Fontes, 2005 p. 129-138.

Recebido em: 30/10/2015

Aprovado em: $23 / 12 / 2016$ 